\title{
Bright Gold Electroplating Solutions
}

\author{
TYPES OF BRIGHTENING ADDITIVES USED
}

\section{Guy Bacquias}

Consultant, Béthune, France

\begin{abstract}
In electroplating, the formation of bright deposits is desirable in order to avoid extra buffing costs and also as a means of getting an acceptable finish on areas not accessible to micro-mechanical finishing tools. This constraint is particularly important in the deposition of gold, as losses of the metal during buffing or other mechanical finishing operations must be kept to a minimum.
\end{abstract}

Although baths giving bright deposits of certain other metals were developed earlier, the first bright gold plating solutions appeared around 1960 when it was found that codeposition of certain other metals with the gold resulted in bright deposits. The first satisfactory bright gold plating baths were therefore essentially alloy plating baths and in the absence of an understanding of the principles involved in alloy plating, they were developed empirically.

Alkaline cyanide solutions of gold plus copper were found which produced deposits in which the brightness of the substrate was preserved at deposit thicknesses up to 12 to 15 $\mu \mathrm{m}$. Additions of organic substances were found to reinforce the brightening effect of base metals, and baths became complex in composition. In the same cyanide bath, for example, cadmium, nickel and gelatin might be found along with gold and copper. Complexing agents such as ethylenediaminetetra-acetic acid (EDTA) and diethylene pentamine traicetic acid (DPTA) were introduced into such alloy plating baths for the first time as a means of controlling the codeposition of the brightening base metals with the gold. The replenishment and maintenance of these baths proved very difficult at the time, since sophisticated methods of analysis such as spectrometry and Auger electron spectrography were not in general use. These solutions nevertheless found application for the deposition of decorative coatings.

For plating solutions giving bright gold deposits of purity 23 carat or more, industry had to wait for the discoveries of Rinker and Duva (1) on the use of gold cyanide in buffed acid solutions. At the same time further developments of practical brightening and levelling agents made possible the deposition of coatings of thicknesses of up to $10 \mu \mathrm{m}$ or more, the brightness of which equalled or even exceeded that of the substrates upon which they were plated. Also, the deposits were not so internally stressed that their adhesion to the substrate was affected detrimentally.

At the present time, using either alkaline or acid cyanide, or sulphite solutions, bright gold or gold alloy coatings can be readily achieved at thicknesses of up to 20 or $30 \mu \mathrm{m}$. Much thicker deposits can be produced from specially formulated electroforming solutions.

\section{Acid Bright Gold Plating}

Acid gold plating solutions were originally developed for, and used in, the field of electronics, particularly for edge contact areas in printed circuit boards, the plastic substrate of which could withstand neither the high temperature nor the alkalinity of conventional cyanide baths. Since then, acid gold plating solutions have found wide use in jewellery applications, partly because of the high wear and corrosion resistances of the deposits, and partly because of the uniform brightness of coatings up to several micrometres in thickness.

All the acid electrolytes that are presently in use are alloy plating baths, the gold being codeposited with nickel, cobalt or iron. The gold-iron solutions are not extensively employed at present, although they produce coatings of a pleasant colour and genuine brightness. Gold-nickel solutions are more widely used, but the pale colour of the deposits has not gained wide acceptance in jewellery applications. Electrolytes based on gold-cobalt codeposition are by far the most extensively used. They derive directly from the first formulations proposed by Rinker and Duva (1), their basic composition being:

$\begin{array}{lr}\text { Gold (as potassium gold cyanide) } & 4 \text { to } 12 \mathrm{~g} / 1 \\ \text { Citric acid } & 20 \text { to } 70 \mathrm{~g} / 1 \\ \text { Potassium citrate } & 50 \text { to } 90 \mathrm{~g} / 1 \\ \text { Cobalt (as sulphate) } & 1 \text { to } 3 \mathrm{~g} / \mathrm{l}\end{array}$

These solutions are operated at a temperature of between 29 and $35^{\circ} \mathrm{C}$, with a pH value between 3.2 and 4.0 . If required, the $\mathrm{pH}$ can be adjusted with citric or phosphoric acid, the latter being more particularly used when the bath contains a complexing agent. The current densities used range from 0.8 to $2 \mathrm{~A} / \mathrm{dm}^{2}$. The efficiencies of such solutions are rather poor and rarely exceed 30 per cent. This figure can be considerably improved when aluminium is added to them as formate or oxalate (2). In these circumstances cathode efficiency can be over 77 per cent.

Under normal conditions the codeposited cobalt is 
responsible for brightening gold. This, to a lesser degree, is also true for codeposited nickel and iron. However, full brightness can be achieved only for thin deposits. As soon as the thickness exceeds $3 \mu \mathrm{m}$ a tendency for the deposit to 'burn' at high current densities is observed, the bright appearance gradually changing to satin, then dull. Moreover, if the bath does not include any addition agents other than the primary alloying metal, the deposit is susceptible to hydrogen embrittlement as a result of the poor cathode efficiency. Consequently, when thick bright coatings $(5 \mu \mathrm{m}$ and over) are required, it is necessary to add various complementary additives which affect deposit properties such as brightness and internal stress. For example, the addition of indium sulphate considerably increases the brightness of gold-cobalt deposits in complexed baths, without simultaneously increasing deposit embrittlement. On the other hand, in a non-complexed solution such additions of indium sulphate produce high internal stresses.

Although the use of complexing or chelating agents tends to decrease efficiency (typically down to 23 or 24 per cent), it ensures hard and bright deposits up to $20 \mu \mathrm{m}$ in thickness. In addition their use drastically reduces the formation of cobaltcyanide complexes (3), the presence of which is associated partly with embrittlement of gold coatings. The following formulation can produce bright gold-cobalt deposits for jewellery items:

$\begin{array}{lr}\text { Gold (as potassium gold cyanide) } & 6 \mathrm{~g} / 1 \\ \text { Citric acid } & 25 \mathrm{~g} / \mathrm{l} \\ \text { Potassium citrate } & 80 \mathrm{~g} / 1 \\ \text { Cobalt sulphate } & 9 \mathrm{~g} / 1 \\ \text { EDTA (Sodium salt) } & 15 \mathrm{~g} / 1 \\ \text { Indium (as sulphate) } & 0.4 \mathrm{~g} / 1 \\ \text { pH (adjusted with phosphoric acid) } & 3.2\end{array}$

The operating life of electrolytes of this type is practically unlimited. Some have been working for over 15 years and are still achieving consistent and high quality results.

In baths containing no complexing agent, other brighteners can be used. These are mainly of the organic type. Some derivatives of pyridine, which can be added in comparatively large concentrations, either alone or associated with saccharin, sodium naphthalene trisulphonate, or $p$-toluene sulphonamide, considerably increase the brightness and levelling of the deposits, whether these are gold-cobalt or gold nickel.

\section{Alkaline Cyanide Pure Gold Electrolytes}

These are very rarely used in the field of jewellery for the deposits do not offer the mechanical properties required to resist the normal handling to which these articles are subjected. Nevertheless, it should be mentioned that pure gold bright deposits can be achieved, for example by adding to the solutions Turkey Red oil (sulphonated castor oil) together with potassium xanthate and/or a mercaptan such as mercaptobenzothiazol. In this case, the proportion of free cyanide in the solution should be comparatively high (at least $50 \mathrm{~g} / 1)$. The operating temperature of such solutions is between 60 and $80^{\circ} \mathrm{C}$. Turkey Red oil can be replaced by other tensioactive compounds, especially by phosphonic wetting agents of the ALKAPENT type.

The presence of arsenic in solutions at a concentration of a few parts per million also increases the brightness of gold deposits without it being incorporated in them in any significant amount.

\section{Alkaline Cyanide Alloy Gold Electrolytes}

There are many alkaline cyanide baths containing alloying metals from which bright gold can be deposited, but only those that can be used easily under industrial conditions and are in current use for decorative applications are considered.

\section{Gold-Silver}

Solutions for the deposition of gold-silver alloys are widely used in the costume jewellery industry. Mostly, they are used to form intermediate coatings, the final deposit being produced from an acid bath which confers a good wearresistant finish together with very low porosity and, therefore, good corrosion resistance.

The gold-silver alloy deposits are usually of 16 or 18 carat quality, depending on the bath composition and the operating parameters. The electrolytes that are used contain a high proportion of free cyanide and operate at room temperature. Only low current density, not in excess of $1 \mathrm{~A} / \mathrm{dm}^{2}$, can be applied when using these solutions. Brightness is achieved through the addition of metallic complexes containing organic ligands and by the codepositing silver. The degree of agitation of the parts (or of the solution) also plays a part in determining the level of brightness. The thickness of deposits produced from these solutions is rather limited. In spite of a reasonable plating efficiency, there is considerable hydrogen occlusion causing embrittlement of the coating. This is increased further by the presence of nickel in solution, although this element cannot be found in the deposit. A typical formulation for bright gold-silver alloy deposition which has been described in the literature is:

$$
\begin{aligned}
& \text { Gold (as potassium gold cyanide) } \\
& \text { Silver (as cyanide) } \\
& \text { Free cyanide (potassium) } \\
& \text { Potassium nickel cyanide } \\
& \text { Wetting agent (non-ionic) } \\
& \text { Amine derivative } \\
& \text { Thiosulphate }
\end{aligned}
$$




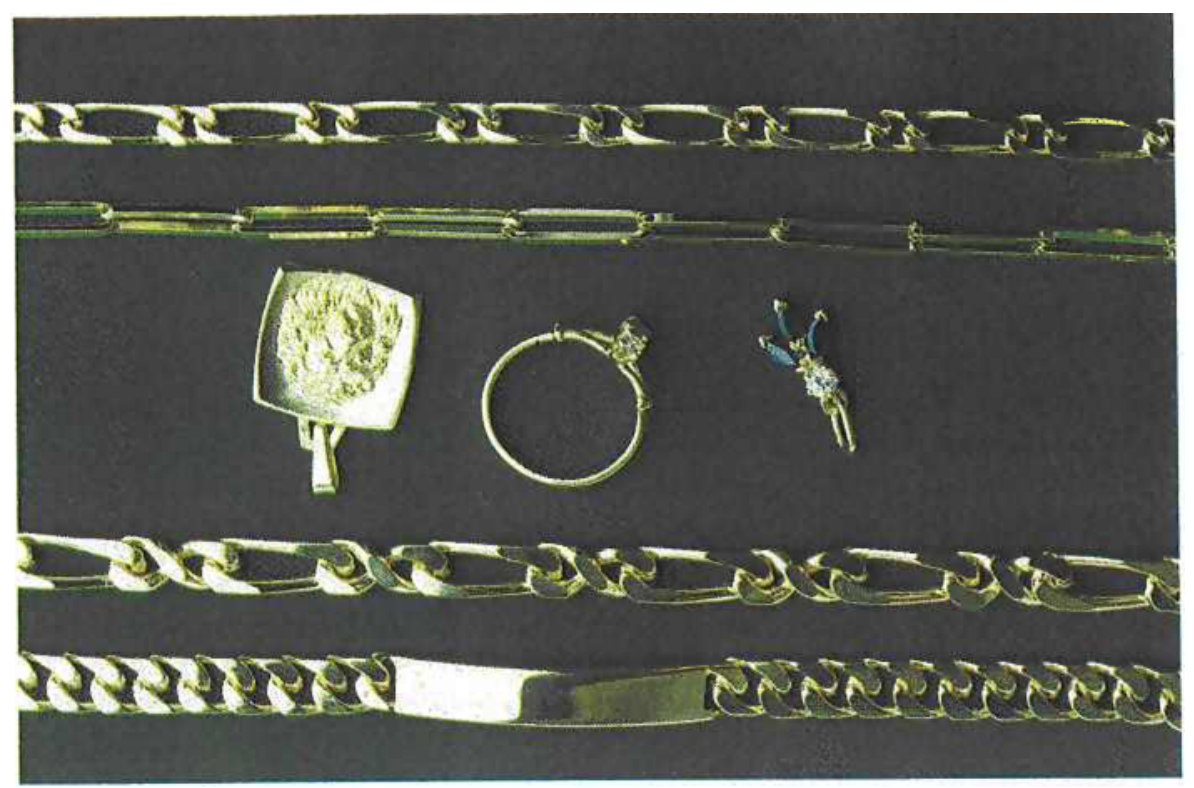

Fig. 1 Gold-copper-cadmium plated jewellery (20 $\mu \mathrm{m}$ thick).

Photograph by courtesy of Sociêté Alinox, Lyon

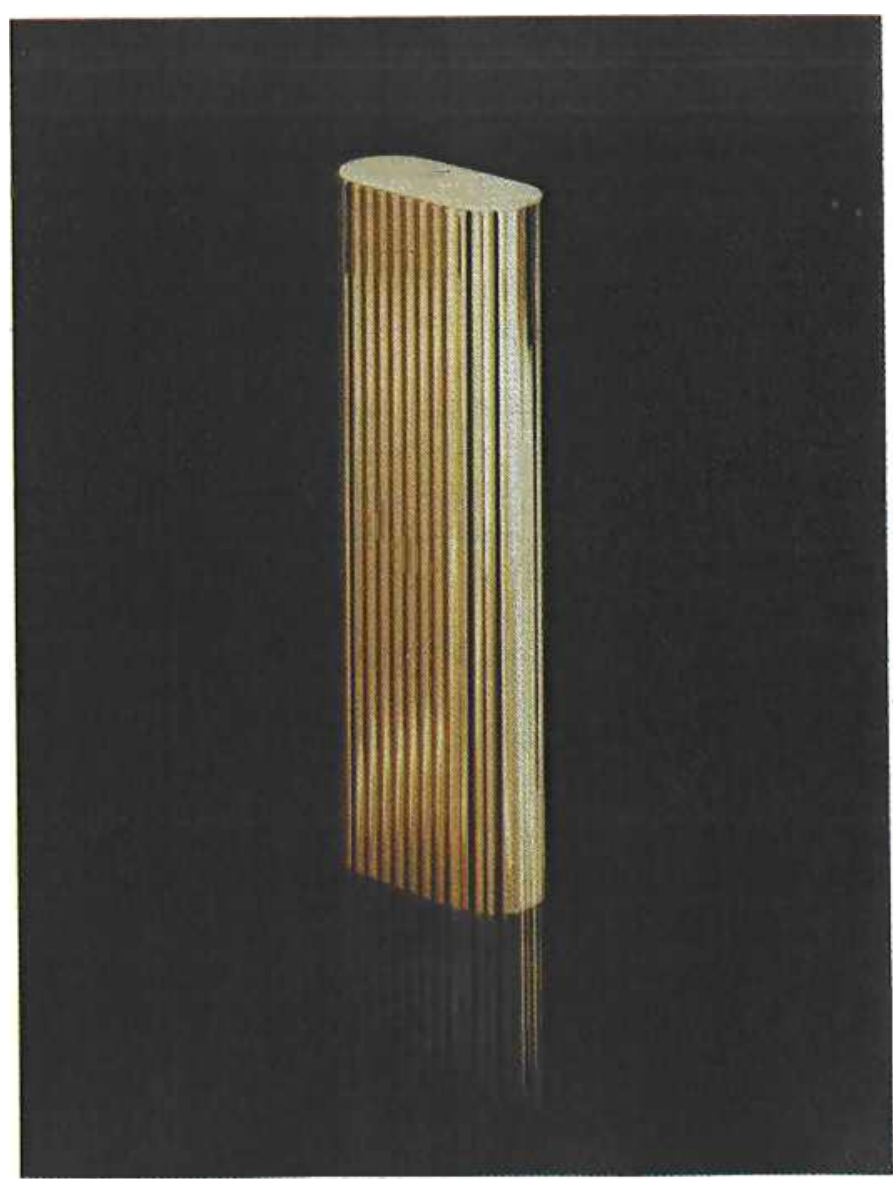

A slight modification of this basic formula allows the deposition of bright gold-silver alloys of 14 carat purity. Such deposits can offer an interesting base for 24 carat finishing coatings when the cost of gold is very high. It should be pointed out, however, that difficulties have been experienced with these solutions in maintaining 14 carat purity and ensuring satisfactory corrosion resistance (4). The main difference between this and the original electrolyte lies in the proportion of free cyanide present - only 6 to $10 \mathrm{~g} / \mathrm{l}$ for the deposition of 14 carat alloys - solution conductivity being maintained by an alkaline phosphate at concentration of at least $100 \mathrm{~g} / 1$.

The use of nickel in gold-silver solutions is tending to decrease, other metals such as antimony or even selenium being used in its place. The presence of some amine is essential for brightness and it is advisable to use a phosphonic wetting agent in addition to this.

Fig. 2 Gold-plated lighter ( $5 \mu \mathrm{m}$ gold-silver plus $5 \mu \mathrm{m}$ gold-cobalt). Photograph by courtesy of 'Les Must de Cartier', Paris 


\section{Gold-Nickel and Gold-Cobalt}

Whereas acid gold-cobalt and gold-nickel plating solutions are suitable for decorative as well as for electronic applications, alkaline solutions, because of their high $\mathrm{pH}$ and their relatively high operating temperature $\left(60\right.$ to $\left.80^{\circ} \mathrm{C}\right)$, are used only for decorative applications. They achieve very bright deposits with much greater efficiencies than do acid baths. The hardness of the coatings is also considerable and confers very good resistance to abrasive wear.

Deposited alloy brightness depends upon different parameters such as the codeposition of alloying metal, the concentration of free cyanide, the addition of a non-ionic wetting agent and the presence of a third metal, such as selenium, in solution at the concentration level of a few parts per million. Generally, selenium cannot be detected in the alloy deposit and it is thought that it operates as a 'catalyst' rather than as an alloying metal.

A typical alkaline cyanide solution for depositing goldnickel is:

Gold (as potassium gold cyanide)

Nickel (as cyanide)

Selenium

Free potassium cyanide

Phosphate (potassium)

Carbonate (potassium)

Wetting agent (phosphonic)

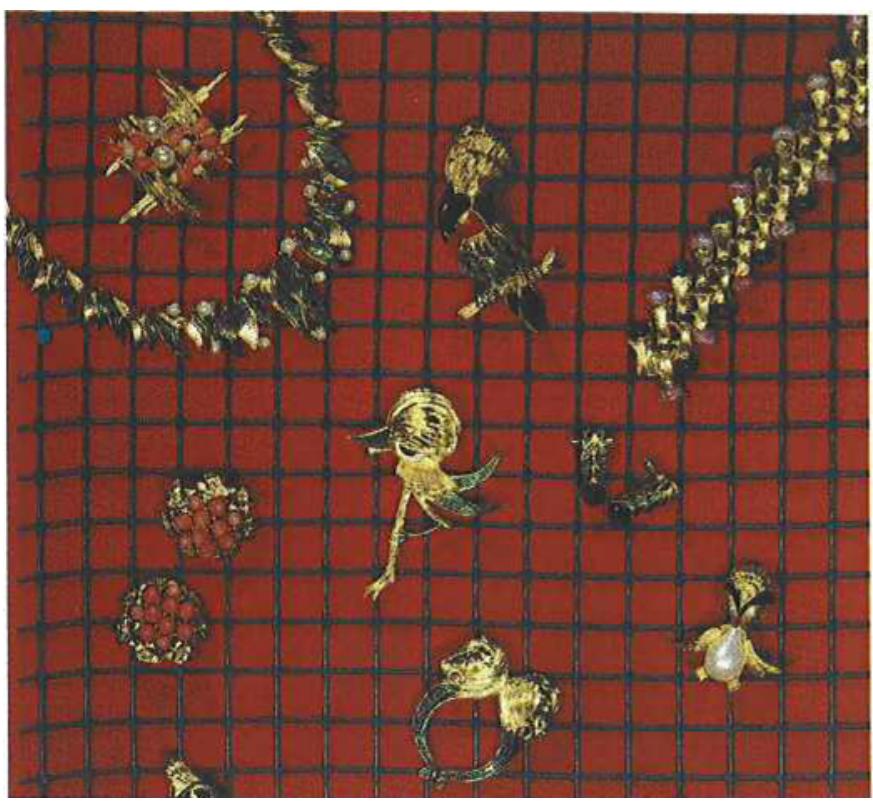

Fig. 3 Gold-plated costume jewellery by Carven $(5 \mu \mathrm{m}$ gold-cobalt on nickel-plated tin alloy.

Photograph by courtesy of Gonthiez Freres S.A., Paris

This type of electrolyte operates at a temperature of 60 to $65^{\circ} \mathrm{C}$ within a current density range of 0.3 to $1 \mathrm{~A} / \mathrm{dm}^{2}$. Contrary to what is observed with the corresponding acid cyanide baths, the codeposition of cobalt or nickel with the gold has virtually no effect on the colour of the deposit, and the alloying element acts only as a brightener. One particular point must be stressed regarding the electrolyte preparation. Double potassium/cobalt or / nickel cyanide must be added

Fig. 4 Gold-plated vermeil jewellery ( $2 \mu \mathrm{m}$ gold cobalt plus $15 \mu \mathrm{m}$ gold-copper-cadmium on sterling silver).

Photograph by courtesy of Société Alinox, Lyon

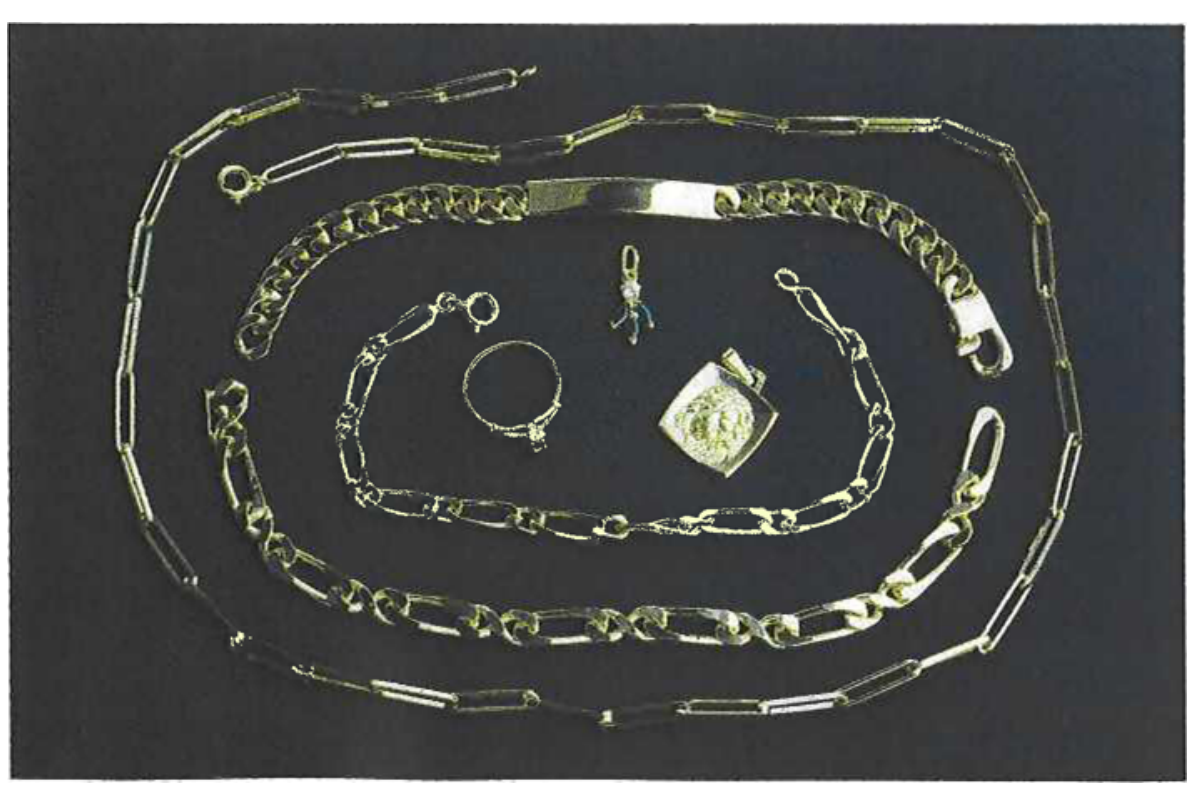


when it is freshly prepared. It is therefore advisable on making up such an electrolyte to prepare the necessary double metallic cyanide directly from nickel or cobalt chloride and potassium cyanide. The chloride ion in solution does not affect unfavourably the efficiency of the electrolyte, and good quality stainless steel anodes are not corroded.

\section{Gold-Copper-Cadmium}

Coatings of these alloys are very widely used in the field of costume jewellery. They are bright and level to a considerable thickness. The solutions can even be used for electroforming articles as thick as 0.3 to $0.5 \mathrm{~mm}$. Brightness and levelling are essential to ensure successful electroforming within this thickness range. The first gold-copper-cadmium baths appeared when cadmium was added for the purpose of brightening to electrolytes that had been employed exclusively to deposit gold-copper binary alloys. In the Latin countries, pink gold has always been in great demand and, from the beginning of the sixties, 18 carat gold-coppet alloys were electrodeposited and offered a colour similar to that of metallurgically prepared gold-copper alloys. The main problem in the addition of the third metal was two-fold, on the one hand colour uniformity and caratage had to be kept and on the other a bright deposit had to be produced. The first attempts were made with additions of silver as the third alloy metal. A few solutions operating at neutral $\mathrm{pH}$ (3.7 to 6.8 ), and practically without free cyanide, gave ternary alloy deposits that were relatively bright up to $10 \mu \mathrm{m}$ in thickness, but bath control was difficult. Moreover, the colour obtained was not sufficiently similar to that of alloys formed from the metallurgical route. Cadmium was then used instead of silver as a brightener, and was soon shown to be very effective.

The concentration of cadmium originally used in the electrolyte ranged from 50 to $80 \mathrm{ppm}$ as complexing agents were not yet in industrial use and the metal was added in the form of a simple salt. The basic formulation of electrolytes was fixed in a very empirical manner. The concentration of gold was generally around $1 \mathrm{~g} / 1$, whereas that of copper vatied between 4 and $8 \mathrm{~g} / 1$. It was well known that the $\mathrm{pH}$ had to temain between 10.0 and 10.5 , but the role played by the free cyanide was very uncertain; its maximum concentration was arbitrarily fixed at between 8 and $10 \mathrm{~g} / 1$. The current densities used did not exceed $0.4 \mathrm{~A} / \mathrm{dm}^{2}$ and the operating temperatures varied from 60 to $90^{\circ} \mathrm{C}$. Colloids such as gelatin and dextrin were used as artificial ageing components fot the baths and they contributed slightly to brightening. In spite of this ad hoc approach, brightness could be achieved for deposits up to 15 to $20 \mu \mathrm{m}$ in thickness, at an average plating rate of 10 to $12 \mu \mathrm{m}$ per hour. The amount of cadmium in the deposited alloys was a maximum of about 3 to 4 per cent, but this concentration was sufficient to give the desired level of brightness.

The electrolytes for the deposition of gold-coppercadmium alloys have now been developed to the stage of satisfactory industrial use and their operating and maintenance conditions are well defined. Thus, the concentration of copper (as metal) must be at least 15 times that of metallic gold, whereas the concentration of free cyanide must be about half that of metallic copper. Tensioactive compound additions are not essential as far as brightness is concerned, however, their importance in helping to ensure satisfactory plating cannot be overlooked. The phosphonic derivatives appear to be superior to sulphonic ones. It is advisable that amines should be present; triethanolamine, for instance, is an excellent complementary additive for brightness. However, the basic brightener in the formulation is cadmium.

Owing to the use of chelating agents such as EDTA, DPTA, nitrilotriacetic acid (NTA) and others, the concentration of cadmium may increase to between 1.5 and $2.0 \mathrm{~g} / \mathrm{l}$, the amount of it which is codeposited depending on the plating current density. Gold-copper-cadmium alloys that are now deposited on costume jewellery contain 12 to 14 per cent cadmium, mainly as a substitute for copper, thus giving the alloys an improved resistance to corrosion and tarnishing. Because of the high concentration of cadmium now possible in the electrolyte through the use of chelating agents, there is no practical problem in maintaining brightness, since the concentrations of cadmium and other basic constituents of the electrolyte can be maintained readily within specified ranges in the solution. The concentration of chelating agent is not critical and can reach 7 to $8 \mathrm{~g} / \mathrm{l}$, which allows a high 'reservoir' concentration of cadmium. These principles are utilized in 18 carat gold electroforming baths based on this system.

\section{Additional or Complementary Brighteners}

A new type of brightener, called 'Universal Brightener' (5), which is under French 'Soleon patent' protection, has been commercially available for over a year in France; it is suitable for most of the cyanide electrolytes and it can be used in such baths for gold or gold alloy electrodeposition. It is based essentially on organic materials with one or more metalloids. It is added to the baths in very small quantities and involuntary excesses can be eliminated by the use of activated carbon.

\section{Sulphite Plating Solutions}

About 10 years ago, sulphite-based gold plating baths seemed to have a promising future, but, in spite of their high cathode efficiency, these solutions very quickly fell out of favour, partly because of the high cost of gold sulphite, but 
mainly because of the instability of that compound. Nevertheless, they still find uses and new patents have been taken out for improved formulations of these electrolytes, especially for gold alloy deposition. Because cyanide, and particularly free cyanide, is absent, there is no fear of overcomplexing of the alloy metals, which would tend to inhibit the formation of bright deposits.

A brief review of the patent literature relating to gold sulphite electrolytes in recent years readily illustrates the wide variety of brightening additives used in these solutions. A U.S. patent claiming a pink gold-palladium alloy plating formulation (6) does not specify a brightening agent, but it is significant that typical baths contain a small amount of sodium arsenite $(30 \mathrm{mg} / 1)$ plus a very low concentration of copper sulphate $(95 \mathrm{mg} / \mathrm{l})$. Like the palladium itself, the copper and arsenic probably function as brighteners.

In a U.K. patent, the brightener is an amidopolyphosphate (7). One of the formulations given is as follows:
Gold (as sulphite)
Sodium sulphite
$8 \mathrm{~g} / 1$
$10 \mathrm{~g} / 1$
$30 \mathrm{~g} / 1$
Sodium pyrophosphate
$20 \mathrm{~g} / 1$
Ammonium amidopolyphosphate

Such a bath operating at $\mathrm{pH} 8.5,49^{\circ} \mathrm{C}$ and $0.3 \mathrm{~A} / \mathrm{dm}^{2}$ is claimed to give very bright deposits.

A Swiss patent (8) may also be mentioned. It claims an ammoniacal gold sulphite bath into which copper is added in the form of the EDTA complex, in order to form a pink 19 carat alloy deposit. Here, the brightener, which is not explicitly defined in the patent, is probably ammonium thiosulphate, perhaps combined with ammonium citrate which is added as a buffer.

As with most other gold electrolytes, either acid or alkaline, an organo-metallic combination generally appears to be the ideal combination for conferring brightness to the deposits obtained from gold sulphite baths.

\section{Effect of Brighteners}

In any electroplating process, the effect of brighteners is to modify the microstructure of the deposits by promoting a particular electrocrystallization orientation.

The structure may be altered so that either lamellar or columnar grains are obtained. The results can be beneficial or detrimental according to service conditions to which gold plated parts will be subject. For decorative applications such as costume jewellery, on which this article is based, the three basic requirements are high brightness, effective levelling and low porosity of the deposits. The latter factor is especially important as far as jewellery items are concerned, because human perspiration can strongly attack the substrate through pores. Failures caused by such attack are specially noticeable in humid climates. It is therefore of the utmost importance that the brighteners in use, or the operating conditions, do not give rise to porosity in the deposits. It is known that the nature of the substrate, particularly its pre-plating mechanical and chemical preparation, may promote porosity in electrodeposits (9) and it is always advisable to begin with a strike alloy of gold-cobalt or gold-nickel deposited from an acid bath to minimize porosity (10). Furthermore, this strike, which should be at least 0.2 to $0.3 \mu \mathrm{m}$ thick, is an effective barrier between the substrate and the gold subsequently deposited, particularly if the latter is in the form of goldsilver or gold-copper-cadmium coatings, and promotes excellent adhesion between the coatings and the substrate.

Levelling is not always a beneficial quality for it can mask and even entirely obliterate delicate patterns worked on the substrate prior to plating. This effect is generally the result of adsorption of organic additives at promontories in the growing deposit and subsequent inhibition of deposition of gold at these points. Levelling very often contributes to the enhancement of brightness of deposits although the condition for brightness is primarily the presence of organic and/or metallic additives in the bath and their influence on the deposit crystal growth. Most such additives tend to produce internal stresses in deposits and they must be used with care. In some cases it is even necessary to heat treat the deposits to avoid possible cracking. The combination of organic and metallic additives to the electrolytes complicates the identification of processing problems and the fact that sheer brightness is achieved does not always mean that the deposit is 'satisfactory'.

Nevertheless, it can be said that the moderngeneration of bright gold deposits shows an impressive improvement over the earlier one. When the correct choice of process for a given application is made, and care is taken in its operation and maintenance, superb results can be achieved.

\section{References}

1 E.C. Rinker and R. Duva, Sel-Rex Corp., U.S. Patent 2,905,601 (1959)

2 Oxy Metal Industries Cotp., U.S. Patent 4,069,113 (1979)

3 R.L. Cohen, F.B. Koch, L.N. Schoenberg and K.W. West, J. Electrochem. Soc., 1979, 126, (9), 1608-1618

4 Anon., Gold Bull., 1982, 15, (1), 24

5 G. Bacquias, Oberfläche-Surface, 1981, 22, (3), 79-81

6 Oxy Metal Industries Corp., U.S. Patent 4,048,023 (1978)

7 Oxy Metal Industries Corp., U.K. Patent 1506496 (1973)

8 Bugnion S.A., Swiss Patent 595,463 (1978)

9 J.M. Leeds, Trans. Inst. Met. Finish., 1969, 47, 222-227

10 R.J. Morrissey and A.M.Weisberg, Trans. Inst. Met. Finish., 1980, 58, 97-103 